\title{
FAKE NEWS E DEMOCRACIA À LUZ DO PENSAMENTO DE HANNAH ARENDT
}

\section{Camilla Tavares de Albuquerque ${ }^{1}$ Paulo Roberto Fogarolli Filho ${ }^{2}$}

Resumo: O presente artigo trata da questão das fake news, analisando-a sob a perspectiva do pensamento de Hannah Arendt, dando especial atenção aos seus conceitos de verdade factual e ação dialógica. Inicialmente, abordou-se a relação entre a fake news e a verdade, delimitando a relação entre ambas. A partir daí, foi feito um estudo por meio de metodologia analítico-dedutiva para analisar o papel da verdade e da mídia na política e, especificamente, suas reverberações na democracia.

Palavras-chave: Fake News; Verdade; Mídia; Hannah Arendt; Democracia.

\section{FAKE NEWS AND DEMOCRACY IN THE LIGHT OF HANNAH ARENDT'S THOUGHTS}

\begin{abstract}
This article deals with the issue of fake news, analyzing it from the perspective of Hannah Arendt's thought, paying special attention to hers concepts of factual truth and dialogical action. Firstly, it was analysed the relationship between fake news and truth, delimiting the relationship between them. From there, it was made a study using analyticaldeductive methodology to analyze the role of truth and the media in politics and, specifically, its reverberations in democracy.
\end{abstract}

Keywords: Fake News; Truth; Media; Hannah Arendt; Democracy.

\section{INTRODUÇÃO}

O aperfeiçoamento dos meios tecnológicos nas últimas décadas aliado ao uso intenso da internet serviu como verdadeira mola propulsora para a exponencial disseminação das fake news na sociedade hodierna.

\footnotetext{
1 Mestranda em Direito da Sociedade da Informação pelo Centro Universitário das Faculdades Metropolitanas Unidas - FMU (São Paulo). Graduada em Direito pela Universidade Federal de Pernambuco. Delegada de Polícia Civil do Estado de São Paulo. E-mail: albuquerque.camilla33@gmail.com - http://lattes.cnpq.br/9570276997068133 https://orcid.org/0000-0002-1431-150X

2 Mestrando em Direito da Sociedade da Informação pelo Centro Universitário das Faculdades Metropolitanas Unidas - FMU (São Paulo). Especialista em Direito do Trabalho e Processo do Trabalho pela Pontifícia Universidade Católica de São Paulo. Graduado em Direito pelo Centro Universitário das Faculdades Metropolitanas Unidas FMU (São Paulo). Advogado. E-mail: paulofogarolli@duartegarcia.com.br http://lattes.cnpq.br/8919039318088450 - http://orcid.org/0000-0002-2860-9040
} 
As redes sociais surgem desse recente e evoluído aparato tecnológico, servindo como novo palco dos debates políticos, retirando da mídia o poder central de discussões que outrora comandava a sociedade.

Discute-se, atualmente, o poder midiático que cada indivíduo detém na sociedade, justamente pela facilidade que os meios tecnológicos - em especial as redes sociais -, propiciaram para a criação, divulgação e reprodução de informações pelos próprios indivíduos. Hoje, com apenas um clique, é possível divulgar uma notícia pelas redes sociais, tornando-a visível para uma infinidade de pessoas.

Daí a importância de analisar o tema da verdade e o papel desempenhado pela mídia no campo da política e, especialmente, para a democracia.

Nesse trabalho, objetivando o tema das fake news, adotou-se como referencial teórico principal a obra de Hannah Arendt, em especial seus conceitos de verdade factual e ação dialógica.

Inicialmente, optou-se por fazer uma análise aprofundada acerca da relação entre as chamadas notícias falsas e aquilo que se entende por verdade, notadamente no contexto da sociedade da informação, cuja marca característica é a imersão das relações sociais no ambiente tecnológico interconectado em rede (internet).

Para tanto, utilizou-se os referenciais teóricos de Manuel Castells (2019) e Paul Virilio (1996), especialmente sobre a relevância da informação da nova estrutura social, constituindo novo "paradigma informacional", assim como o papel da velocidade sentida pela sociedade moderna, pautada pela "instantaneidade dos fatos" e da circulação da informação.

Após, o tema foi estudado à luz do pensamento arendtiano, analisando como as fake news são capazes de fazer cessar o diálogo e figurar como instrumentos daquilo que aqui se denominou "contra-político".

Para levar a cabo o estudo, adotou-se uma metodologia analítica, realizada por meio de pesquisa bibliográfica e de caráter dedutivo. Os temas foram analisados de forma crítica, na tentativa de entender o fenômeno das fake news a partir do pensamento de Hannah Arendt, sem excluir demais autores que tratam do tema.

A busca pelo diálogo proposto por Hannah Arendt alinha-se com o resgate de uma consciência coletiva em torno da responsabilidade das notícias que circulam na sociedade, trazendo ao contexto atual um repensar da liberdade de expressão, a qual deve ser limitada pelo exercício de uma democracia plural, responsiva, participativa e dialógica. 


\section{VERDADE E FAKE NEWS}

A expressão fake news está cada dia mais presente nos debates nas diversas esferas sociais, justamente pela produção de impactos no campo político, jurídico, filosófico e social, tornando-a um fenômeno mundial. As notícias fraudulentas, também chamadas de Fake News (ABBOUD; CAMPOS, 2020), foram consideradas como "palavra do ano" em 2017 e a expressão foi colocada no dicionário britânico da editora Collins.

Não obstante seja uma expressão de grande repercussão social atual, muitos analistas apontam que as fake news não são um fenômeno recente, a exemplo de Macedo Júnior (2020) que indica que "a disseminação de notícias falsas não é nenhum evento novo na história", e indica o discurso de Papa Francisco, de 2018, ao sugerir que as Fake News "datam até mesmo do Jardim de Éden”. Nesse contexto, Tofolli (2020) aponta que boatos, lendas urbanas, mentiras espalhadas maliciosamente, sempre existiram, e cita um desenho datado de 1984, do cartunista Frederick Burr Opper, no qual um cidadão segurava um jornal com o termo fake news, representando o alvoroço decorrente dos boatos.

No entanto, o aperfeiçoamento dos meios tecnológicos nas últimas décadas, aliado ao uso intenso da internet, serviu como verdadeira mola propulsora para a exponencial disseminação das fake news na sociedade hodierna. A internet modificou as referências sobre o espaço e o tempo fundindo o mundo virtual ao real (RAIS, 2020).

Esses novos meios tecnológicos podem ser exemplificados pelo aprimoramento da tecnologia da informação e comunicação (TIC), com o surgimento das redes sociais (Facebook, Youtube, Instagram, Twitter), pelos aplicativos de conversação instantânea (WhatsApp), bem como pela Inteligência Artificial, tecnologia que pressupõe a programação de algoritmos, sequências de linhas de códigos repletas de complexos cálculos matemáticos, os quais são alimentados por incalculáveis quantidades de dados (BARRETO JUNIOR; SPAREMBERGER, 2020, p. 178).

Nesse cenário, Pierre Lévy (1999, p. 19) empresta a expressão de "dilúvio de informações" de Roy Ascott para retratar o impacto da tecnologia no mundo moderno e aborda que esse "transbordamento de informações" acarreta a "confusão dos espíritos":

A quantidade bruta de dados disponíveis se multiplica e se acelera. A densidade de links entre as informações aumenta vertiginosamente nos bancos de dados, nos hipertextos e nas redes. Os contatos transversais entre os indivíduos se proliferam de forma anárquica. É o transbordamento caótico das informações, a inundação de 
dados, as águas tumultuosas e os turbilhões da comunicação, a cacofonia e o psitacismo ensurdecedor das mídias, a gerria das imagens, as propagandas e as contrapropagandas, a confusão dos espíritos.

Essa “inundação humana" de informações tratada por Pierre Lévy pode ser associada à "violência da velocidade" constatada por Virilio (1999, p. 137), uma vez que a sociedade é subjugada à aceleração e à velocidade, tornando-se "simultaneamente, o lugar e a lei, o destino e a destinação do mundo".

A sociedade, portanto, está diante de um "paradigma informacional" (CASTELLS, 2019, p. 124), centrada na "era da informação", pois como a informação é parte integral de toda a atividade humana, todos os processos de nossa existência individual e coletiva são diretamente moldados pelo meio tecnológico.

O novo contexto social altamente tecnológico, denominado como "sociedade da informação", na qual a informação é o "centro gravitacional" (BARRETO; NASPOLINI, 2019, p.139) da nova era, modificou, principalmente, a forma de comunicação e interação social, conforme explicado por Virilio (2017, p. 22):

\begin{abstract}
A comunicação a distância (primeiro individualizada, depois em massa e, mais recentemente, digital e híbrida) - configuração epocal dessa técnica ressignificada pela velocidade - se reescreve no espaço eletromagnético e reescalona historicamente no e pelo "tempo real", sob a lógica da instantaneidade, no limite tutelar da luz; submete os signos não somente à massificação e depois à informatização da cultura, mas também à experiência histórica irreversível da enfermidade e da reciclagem permanente. Em efeito de encadeamento extenso, o planeta é suspenso na e pela sociabilidade articulada em rede e, ao mesmo tempo, se reinventa nas novas espacialidades dos contextos glocais de acesso/recepção/retransmissão/irradiação de informações, dados, mensagens, imagens, vídeos etc.
\end{abstract}

Essa sociabilidade articulada em rede sentida por Paul Virilio, ou então, a denominada "virtualização" das relações sociais apontada por Sodré (2002, p. 124), desencadeia uma nova forma de visibilidade, pois não há mais a necessidade da "co-presença" para o indivíduo ser visto pelo outro - ou até mesmo pela coletividade -, eis que agora o indivíduo pode ser visto em qualquer lugar do globo, de forma instantânea, através dos aparatos tecnológicos disponíveis, a exemplo de smartphones, notebooks, todos conectados em rede.

A nova visibilidade considerada "midiática" (THOMPSON, 2008, p. 19) proporcionou verdadeira "exaltação do indivíduo" (LÉVY, 1999, p. 19), considerando que o indivíduo está livre, desatado das propriedades espaciais e temporais do aqui e agora, de modo que as ações 
e acontecimentos estão libertos do compartilhamento do solo comum (THOMPSON, 2008, p. 20).

Nessa esteira, Fogarolli Filho e Waldman (2020, p. 130) indicam uma nova característica da sociedade atual, também chamada de "sociedade midiatizada", qual seja, a capacidade de os indivíduos tornarem-se visíveis com enorme facilidade pela utilização dos aparatos tecnológicos e pelo uso das redes sociais.

Agora, tudo pode ser visto, em proporção que não é possível estimar, isto é, não é possível saber o alcance das nossas palavras, imagens, vídeos, divulgados na internet. Os dados divulgados pela Organização das Nações Unidas sobre a quantidade de usuários da internet em 2019, atingiu o total de 4,1 bilhões de usuários, ou seja, metade da população mundial, revelando tamanho alcance das informações que circulam na rede.

As redes sociais ${ }^{3}$ também formam um ambiente altamente propicio para a divulgação, circulação e compartilhamento de informações, considerando a facilidade de disseminação ("viralizar") de conteúdo e a quantidade de usuários.

Os dados divulgados pela imprensa, revelam que as redes sociais no ano de 2020 atingiram números expressivos de usuários no mundo, como o Facebook que alcançou o número de 2,6 bilhões de usuários ativos por mês no mundo, o Youtube atingiu o posto de $2^{\circ}$ lugar de rede social mais popular no mundo com 2 bilhões de usuários, seguido pelo WhatsApp (2 bilhões), do WeChat (1,2 bilhão) e do Instagram (1 bilhão) de usuários.

Nesse contexto emerge o problema de estudo acerca das fake news e a verdade, pois, conforme adverte Barreto Junior e Sparemberger (2020, p. 178), antes da internet inexistiam ferramentas capazes de transmitir e armazenar tanta informação em tão pouco tempo e completam:

\begin{abstract}
A Sociedade da Informação, iniciada da década de 60 do século 20, parece ter um novo marco histórico a cada momento em que se descobrem maneiras de armazenar e transmitir o maior número de informação pelo menor custo, ocupando menos espaço. $\mathrm{O}$ grande problema dessa era parece ser a capacidade de transformar tudo em informação, enquanto se presume sua veracidade.
\end{abstract}

Nesse turbilhão de informação que se propagam pelo "ciberespaço" (LÉVY, 1999, p. 22) como identificar a "veracidade" da informação?

\footnotetext{
${ }^{3}$ Rucuero citando Wasserman; Faust, 1994 e Degenne; Forse, 1999 explica que uma rede social é definida como um conjunto de dois elementos: atores (pessoas, instituições ou grupos; os nós da rede) e suas conexões (interações ou laços sociais). Uma rede, assim, é uma metáfora para observar os padrões de conexões de um grupo social, a partir das conexões estabelecidas entre diversos atores.
} 
Campos Mello (2020, p. 184) aponta que a dificuldade de se identificar a verdade ou falsidade de determinada informação repousa na construção de "narrativas", as quais são propagadas naturalmente pelas redes orgânicas, que são as pessoas de carne e osso que acreditam naquilo que está sendo veiculado. Essa repetição de informações, o fluxo constante e reiterado de mensagens, leva o sujeito a aceitar certos conteúdos como verdadeiros.

Na mesma linha, Waack (2020) identifica que a expressão fake repousa na aparência de verdade, na semelhança com algo que não se sabe, mas, superficialmente, bem que poderia ser verdadeiro e complementa sua explicação identificando o sentido de fake como uma “disseminação de narrativas consideradas opostas".

Hannah Arendt (2013, p. 455) retratou esse o problema da busca pela verdade pelas informações que circulam na sociedade, justamente por essa "construção de narrativas", trazendo como exemplo as propagandas totalitárias:

\begin{abstract}
A eficácia desse tipo de propaganda evidencia uma das principais características das massas modernas. Não acreditam em nada visível, nem na realidade da sua própria experiência; não confiam em seus olhos e ouvidos, mas apenas em sua imaginação, que poder ser seduzida por qualquer coisa ao mesmo tempo universal e congruente em si. O que convence as massas não são os fatos, mesmo que sejam fatos inventados, mas apenas a coerência com o sistema do qual esses fatos fazem parte.
\end{abstract}

A sedução tratada por Hannah Arendt também foi tratada por Figueira e Santos (2019, p. 43) ao citar a ideia de Marc Ferro no sentido de que a "consciência coletiva que cada sociedade tem de si mesma resulta das narrativas dominantes que, pelas razões mais diversas, se vão impondo em cada momento histórico".

Assim, a sociedade hodierna submersa nesse grande oceano turvo de fake news é pautada pelo embate das narrativas, a busca pela verdade deixou de ser relevante, ou então, na expressão utilizada por Christian Dunker (2017) doravante "é preciso prescindir da verdade", considerando que uma nova expressão cognitiva ascende com um novo tipo de irracionalismo que conseguiu recolocar na pauta temas como: o criacionismo contra o darwinismo, a relatividade da hipótese do aquecimento global, a suspeita sobre a indução e o autismo por vacinas e tantas outras teorias conspiratórias diluídas por um "novo estado da conversa" em escala mundial (DUNKER, 2017).

Desse modo, a verdade lógica abordada por Kant no sentido de sê-la a concordância de um conhecimento com as leis gerais e formais do entendimento e da razão é substituída pelo discurso da "pós-verdade", ou seja, na suspensão completa da referência a fatos e 
verificações objetivas, substituídas por opiniões tornadas verossímeis apenas à base de repetições, sem confirmação de fontes, ou então, quando a ciência silencia e a ideologia faz falar (DUNKER, 2017).

A primazia da ideologia faz erodir os valores democráticos do diálogo, afastando os indivíduos de escolhas refletivas e racionais, colocando-os em verdadeiras "bolhas" que apelem a sua emoção e à crença pessoal, mesmo que não embasados em fatos concretos, do que os fatos verdadeiros em si (PELIZZARI; BARRETO JUNIOR, 2019, p. 63).

Nesse sentido, mostra-se necessário trazer o pensamento de Hannah Arendt sobre o papel da verdade e a ação dialógica no combate as notícias falsas, buscando-se, ainda, resgatar a importância da mídia na divulgação da verdade.

\section{FAKE NEWS E O FIM DO DIÁLOGO EM HANNAH ARENDT}

Se de um lado não é possível falar de fake news sem adentrar o conceito de verdade, tal discussão é de pouca valia se apartada da questão política nela necessariamente envolvida. Falar de fake news exige a reflexão acerca da sua repercussão social e, portanto, dos impactos da verdade (ou da pós-verdade, como se queira) no exercício da política.

Para aprofundar a questão, adotou-se como referencial teórico o pensamento de Hannah Arendt, especialmente no que tange aos conceitos de verdade e ação dialógica trazidos pela autora.

Para Hannah, a verdade aqui tratada se consubstancia no que a autora denomina verdade factual, à qual se contrapõe o conceito de pós-verdade, associado às fake news. A verdade factual, portanto, consiste no conhecimento precário e inicial acerca do objeto, aquele que qualquer pessoa é capaz de alcançar. Por isso mesmo, a verdade, nesse caso, é mais suscetível a manipulações. É o que releva Eugênio Bucci (2016, p. 24):

Esclarece que a verdade factual não se confunde - nem deve se confundir - com outras verdades, aquelas que se pretendem transcendentes ou simplesmente monumentais. A filósofa ressalta que a verdade factual é pequena, frágil, efêmera. Como um primeiro registro dos acontecimentos, um primeiro - e precário - esforço de conhecer o que se passa no mundo, a verdade factual é mais vulnerável a falsificações e manipulações. Mesmo assim, a verdade factual é facilmente reconhecível por todos, pelos homens e mulheres normais, comuns (como os jornalistas profissionais, que são e devem ser homens e mulheres comuns). 
Embora hoje não seja de todo possível associar a verdade factual à informação jornalística, é certo que, para Hannah, essa parece ser uma relação desejável. Daí o relevante papel social atribuído à mídia na democratização do acesso à informação.

Cumpriria à mídia o desiderato de divulgar a informação de acordo com a verdade factual, de forma íntegra e não manipulada. É o que diferencia a verdade factual do discurso político-ideológico, como acentua Bucci (2016, p. 26):

O que parece importar a Hannah Arendt é que a imprensa seja compreendida como um domínio que não está contido naquele outro, o domínio político, embora não deixe de ter um olho ali dentro. De outra parte, a política se define como um domínio que não deve ser inquilino do domínio da imprensa, embora viva tentando lhe pôr o pé na porta.

Isso não quer dizer, no entanto, que a verdade factual deva ser imparcial; deve, tão somente, ser claramente dissociada daquilo que possui caráter opinativo. Com efeito, se um dos corolários da democracia é a liberdade de expressão, esta não pode ser confundida com a imparcialidade nem, por outro lado, com a manipulação.

É nesse estado de coisas que ganha relevo o pensamento arendtiano para a discussão das fake news e de suas reverberações políticas. A divulgação e propagação de notícias manipuladas tem sido capaz de dissipar a verdade factual, convertendo-a em discurso ideológico. Para o bem ou para o mal, as fake news se apropriam dos fatos em prol de uma ideologia particular, tornando irrelevante aos olhos do público o conteúdo da verdade factual.

Trata-se de uma estratégia política - ou contra-política, como se verá adiante - que tem por fito fazer cessar o diálogo. Se tomarmos por base as ideias de Hannah Arendt, a verdade é necessariamente discursiva, mas não ideológica, o que a afasta definitivamente das fake news.

O discurso ideológico por trás das notícias falsas, portanto, tem por objetivo estabelecer um cenário social maniqueísta, em que, ao invés do pluralismo ideológico, tem-se a vigência de dicotomias inconciliáveis - e, portanto, não dialógicas, a exemplo das bolhas sociais (BUCCI, 2016, p. 28):

$\mathrm{Na}$ era das redes sociais, o indivíduo se encontra encapsulado em multidões que o espelham e o reafirmam ininterruptamente - são as multidões de iguais, as multidões especulares, as multidões de mesmos. Vêm daí as tais "bolhas" das redes sociais, cujo traço definidor é a impermeabilidade ao dissenso, a ponto de uma comunidade de uma determinada bolha mal tomar conhecimento da outra. 
A partir do momento em que a própria verdade factual é manipulada e se torna inatingível na sua forma básica, não há mais campo para o pluralismo e, muito menos, para o diálogo. A verdade converte-se em mero subterfúgio para reforçar uma ou outra ideologia, sem que ela mesmo, em si, seja socialmente relevante. Ou seja, importa aquilo que se acredita ser, não aquilo que é.

Tem-se, portanto, o advento do conceito de pós-verdade, já mencionado em sua associação ao mecanismo das fake news, como bem aponta Faustino (2019, p. 144):

\begin{abstract}
Após a popularização da internet e da possibilidade de qualquer pessoa acessar uma infinidade de conteúdo, de informação ou até mesmo conhecimento por meio da rede mundial de computadores e, principalmente, criar qualquer tipo de conceito de verdade, criando nos indivíduos uma sensação de indiferença com ela, pouco importando a relação dessa verdade com a realidade dos fatos ou até mesmo com a credibilidade de uma fonte. Isso dá origem ao conceito de pós-verdade.

(...)

A relação dos indivíduos com o conceito de verdade é bastante relativa e embora a credibilidade de uma informação tenha relação direta com a verdade contida nessa mesma informação, o conceito de pós-verdade mitiga essa relação. Nesse sentido, as crenças pessoais ganham força quando relacionadas com a própria lógica dos fatos, com isso criando uma espécie de crise na forma de como ver e se relacionar com a verdade da informação ou pelo menos com essa ideia da credibilidade da informação.
\end{abstract}

Como consequência deletéria desse processo, tem-se a gradativa dissolução do campo de discussão social característico da esfera pública. A esfera pública é definitivamente o locus de diálogo social, de modo que diluí-la implica na conversão do diálogo em dominação e no consequente risco do advento de autoritarismos.

É precisamente por tal motivo que as fake news são aqui apontados como mecanismos contra-políticos. Explica-se. Se, para Arendt, a política demanda o diálogo plural, não há como haver campo para discussão política sem este. A divulgação de notícias fraudulentas, nesse contexto maniqueísta, apaga pluralismos e diversidades, criando aquilo que ousamos definir como contra-política, numa proposta contra-dialógica.

Para Hannah, é na discussão política, necessariamente na esfera pública, que o homem é capaz de refletir e dialogar, criando uma noção daquilo que a autora denomina destino comum. Assim, as discussões da esfera pública dependem da aquisição da verdade factual, especialmente por meio da ação responsável dos mecanismos midiáticos. Sem o alcance dessa verdade, a discussão política é inviabilizada, sujeito a uma gama de interesses privados convenientemente orquestrados. 
Ressalte-se, nesse ponto, trecho do artigo de Celso Lafer, para quem tanto as mentiras como os segredos corrompem o espaço público (1997, p. 63):

Para Hannah Arendt - como ela explicita em The human condition - o público é simultaneamente o comum e o visível. Daí a importância da transparência do público por meio do direito ex parte populi à informação, ligado à democracia, como forma de vida e de governo, que requer uma cidadania apta a avaliar o que se passa na res publica para dela poder participar. Sem o direito à informação, não se garante a sobrevivência da verdade factual - a verdade da política -, na qual se baseia a intenção e o juízo político, abrindo-se uma margem incontrolada para a mentira e os segredos conservados pelos governantes nas arcana imperii. A transparência do público através de uma informação honesta e precisa é, portanto, condição para o juízo e a ação numa autêntica comunidade política.

Trazendo esse conceito para questões de ordem prática, tem-se que é no campo público que são definidas as políticas públicas, com diretrizes democráticas claras. É então possível discutir sobre leis, regulamentações, controle e ações, definindo um objetivo comum para toda a atuação social.

O processo de privatização de interesses públicos é descrito por Estela Serrano ao mencionar que "o desenvolvimento dos media electrónicos, especialmente a televisão, trouxeram consigo o desenvolvimento de uma cultura cuja tónica é a distracção", e prossegue (SERRANO, 1998, p. 3-4):

O público é agora substituído, na sua função mediadora, por instituições representando interesses privados e partidos, só intervindo raramente e, quando isso acontece, através de "funções aclamativas". As decisões individuais e colectivas são influenciadas por instâncias políticas e/ou económicas.

Diluída a esfera pública, a ação humana se torna contingente, ou seja, há uma perda de parâmetro - ou "perda do fundamento do mundo", para utilizar nosso referencial - que faz com que as maiores atrocidades humanas se tornem possíveis e aceitáveis (TELLES, 1990, p. 24-25):

Para Hannah Arendt, entre os elementos que definem esta capacidade de orientação no mundo - vinculada à compreensão e ao julgamento - está a faculdade de discernir entre a verdade e a mentira e, também, entre o bem e o mal. Isto significa dizer que estas não são categorias que se possa derivar do conhecimento teórico e especulativo - não se trata, portanto, das chamadas verdades da razão. Tampouco podem ser derivadas de valores supremos dados pela cultura, pela tradição ou pela religião e nos quais se tentou tradicionalmente fundar toda moralidade - não se trata portanto de valores situados fora da esfera mundana da própria sociedade. Os critérios de verdade, de justiça e de legitimidade são construídos na experiência intersubjetiva que os homens fazem da realidade do mundo. 
É precisamente a partir desse contexto que Hannah Arendt constrói a ideia daquilo que denominou banalidade do mal, em que pessoas comuns passam a aceitar a prática de atos monstruosos, tema que será abordado adiante, avançando-se para a análise do tratamento das fake news sob a ótica da democracia.

\section{MÍDIA, VERDADE E DEMOCRACIA}

Hannah Arendt chancela o conceito de banalidade do mal a partir dos estudos das atrocidades cometidas especialmente durante a Segunda Guerra Mundial. Para a filósofa, o caso do holocausto é paradigmático no sentido de comprovar como pessoas comuns são capazes de atrocidades de tal monta.

O que salta aos olhos é que os executores das medidas antissemitas acreditavam naquilo que faziam como algo "correto". Eram, portanto, incapazes de diferenciar o bem do mal ou a verdade da mentira na sua forma mais bruta.

Para a autora, isso tudo se devia à ausência do fundamento ético que, portanto, era capaz de tornar a ação humana totalmente contingente e irrefletida. Ou seja, "o problema, diz Hannah Arendt, não é tanto que alguém ou um grupo de pessoas possa se empenhar na mentira organizada. O problema é quando as pessoas passam a acreditar na mentira." (TELLES, 1990, p. 26).

Não por outra razão a divulgação de notícias falsas encontra-se então situada como instrumento contra-político. A partir do momento em que se estabelece a predominância da pós-verdade - e, por conseguinte, a irrelevância da verdade factual em prol de percepções particulares - o que passa a ser propagado, para além da informação, é uma espécie de “discurso de autoridade”, o qual, não raramente, conduz ao chamado discurso autoritário.

Não se trata, no entanto, de uma discussão dicotômica em que, de um lado, tem-se a liberdade a serviço da democracia e, de outro, a política maximizada nos regimes totalitários. A perspectiva arendtiana ensina que a política é capaz de integrar liberdades, sem que, para tanto, tenha que se recorrer necessariamente à defesa do liberalismo. Daí a defesa da fake news como instrumento contra-político, que inviabiliza a ação política, necessariamente dialógica e plural.

Assim, é papel da democracia reconhecer a necessidade de limitações à mídia, sem que disso se dessuma qualquer ofensa ao direito da liberdade de expressão. Tais limitações 
estão abarcadas pela observância ao já aludido destino comum arendtiano, o qual permite a representatividade política plural, nos moldes democráticos.

Ao contrário do que a princípio se poderia imaginar, defender o acesso à verdade factual, como bem apontado por Hannah, significa a defesa da liberdade em sua forma mais pura, permitindo que os indivíduos tirem suas próprias conclusões e criem posicionamentos próprios para sua participação política. É exatamente essa pluralidade de ações aquilo que a autora aponta como saída para a contingência humana em prol da criação de um destino comum. Ou seja, é a partir da ação dialógica que é possível o debate no campo da esfera pública, a criação de parâmetros de atuação comuns a partir de objetivos compartilhados por toda a comunidade.

Analisando a questão das notícias falsas, ou seja, das fake news, Francisco Fonseca releva "se a notícia é, de fato uma mercadoria, o é de um tipo especial e, como tal, necessita ser tratada de forma igualmente especial, tendo em vista as inúmeras consequências que pode acarretar e que assumem cada vez mais dimensões planetárias, dada a mundialização" (2011, p. 47).

A partir dessa responsabilidade midiática é que a questão das fake news exige atenção, especialmente no que tange às suas repercussões na esfera pública e, por conseguinte, no regime democrático. Nesse sentido é que é possível pensar na regulação midiática como mecanismo democrático, que funcionará, ao fim e ao cabo, para preservação do pluralismo político.

Para além disso, o papel informacional da mídia deve ser capaz de produzir o que Fernando Lattman-Weltman denomina "contribuição pan-óptica para a accoutabillity" (2014, p. 53). Para o autor, o mais relevante papel da mídia não é tanto a sua tradicional função instrumental na construção política, mas, sobretudo, "a criação de um efeito pan-óptico, ou seja, a criação de um ambiente de visibilidade possível e razoavelmente não controlada, que pode, a qualquer momento, expor pessoas e instituições públicas a juízo de uma corte fluída e imprevisível” (LATTMAN-WELTMAN, 2014, p. 53).

Analisando o posicionamento do autor, é de se ver que ele não afasta a regulação midiática; diversamente, considera que o ambiente midiático deve promover a visibilidade factual, para o que se exige um razoável controle. Ademais, o controle seria cíclico, de modo que a mídia é "controlada" e, da mesma forma, atua como "instrumento de controle do controlador". 
Tal perspectiva, ao que tudo indica, encontra-se alinhada com a solução arendtiana da ação dialógica, consistente na vida activa. Aliando o pensamento da autora ao controle cíclico característico dos regimes democráticos, seria razoável pensar que a prevalência da verdade factual, em qualquer das esferas de atuação pública, seria capaz de reverter o ciclo contrapolítico das fake news.

Ou seja, a reconfiguração da mídia em prol da verdade factual, seja ela no ato de controle de Estado, seja no ato momento anterior de acesso à informação instrumental para a atuação política estaria apta a requalificar o discurso, realocar a verdade como parâmetro de diálogo e promover a esfera pública.

Para tanto, a regulação midiática é essencial, funcionando como contrapartida inafastável da responsabilidade da mídia na atuação democrática. É o que bem aponta Francisco Fonseca (2011, p. 48):

É claro que, em se tratando da informação, a tentação de se estabelecer controles
autoritários, censórios, é grande, comportamento, aliás, comum na história
brasileira: daí a preocupação com a chamada "liberdade de expressão"
necessariamente dever nortear qualquer mecanismo de controle que venha a se
constituir, tanto em âmbito nacional como internacional, repelindo-se portanto
qualquer tentativa de censura. Mas, como toda liberdade implica responsabilidade,
qualquer conivência - sob pena de legitimação de um efetivo poder sem controle e
mesmo de um pensamento único - quanto à permissividade dos meios de
comunicação é igualmente deletéria à democracia. Afinal, em nome da "liberdade de
expressão", sem a contraparte da responsabilização, observou-se na história a
existência de verdadeiras máquinas de produção de consenso devido à atuação
uníssona "supressora" de vozes discordantes.

O autor se alinha ao pensamento arendtiano ao reconhecer que o imenso poder da mídia exige o seu controle, sob pena de impedir uma espécie de tirania extrainstitucional, anunciando a possibilidade de autoritarismo "de fora para dentro" do Estado. A conexão entre mídia e democracia é evidente em Fonseca para quem "o problema da democratização das instituições, sobretudo da mídia, permanece assim crucial às teorias sobre a democracia, embora seja desenvolvido de forma insuficiente pelas teorias que se debruçam sobre elas" (FONSECA, 2011, p. 56).

Como bem aponta Bucci, é fundamental reconhecer que o problema está "no fato de que, tendo se enraizado no mundo da vida e na esfera pública, elas [as redes] não são públicas em seus controles e na sua propriedade. Sob a malha tecnológica, elas promovem a tecnociência e o capital como substitutos da própria política.”. Assim, reconhecer o poderio e a responsabilidade da mídia sobre a esfera pública é, portanto, um primeiro passo para admitir 
seu controle. Para além de censura, o controle da mídia decorre da sua própria responsabilidade social e é pressuposto da atuação democrática.

\section{CONCLUSÃO}

A liberdade de expressão foi alçada ao seu patamar mais elevado em virtude da utilização dos meios tecnológicos, das redes sociais e do uso da internet, podendo se afirmar que existe uma incontrolável liberdade de opinião na sociedade hodierna.

Multiplicam-se, dessa maneira, opiniões desprovidas de verdade, cujo conteúdo contempla caráter eminentemente ideológico, negacionista e antidemocrático, formadores de discurso do ódio e de grupos totalitários.

Vive-se, dessa maneira, em um cenário de desarranjo democrático, pautado pela circulação veloz de opiniões ideológicas que inundam a mídia e as redes sociais sem qualquer tipo de freio ou contenção, acarretando abusos da liberdade de pensamento e violações aos direitos do outro.

O resgate do diálogo proposto por Hannah Arendt alinha-se com a busca de uma consciência coletiva em torno da responsabilidade das notícias que circulam na sociedade, trazendo ao contexto atual um repensar da liberdade de expressão, a qual deve ser limitada pelo exercício de uma democracia plural, responsiva, participativa e dialógica.

Assim, a mídia deve requalificar o discurso, realocar a verdade como parâmetro de diálogo e promover a esfera pública, a fím de buscar a prevalência da verdade factual, revertendo o ciclo contra-político das fake news.

Nesse contexto, a convivência humana deve ser pautada pela reciprocidade de direitos e deveres, ou então, como inserido na Carta Encíclica PACEM IN TERRIS do Sumo Pontífice Papa João XXIII: “os que reivindicam os próprios direitos, mas se esquecem por completo de seus deveres ou lhes dão menor atenção, assemelham-se a quem constrói um edifício com uma das mãos e, com a outra, o destrói”.

Esse senso de responsabilidade deve pautar a construção do diálogo estabelecido na sociedade hodierna, evitando-se a propagação e difusão de notícias falsas, a manipulação do pensamento, buscando-se, assim, enxotar o discurso do ódio, bem como a expulsão definitiva de regimes totalitários. 


\section{REFERÊNCIAS}

ABBOUD, Geroges; CAMPOS, Ricardo. A autorregulação regulada como modelo do Direito proceduralizado: regulação de redes sociais e proceduralização. In: Fake News e Regulação. Org. ABBOUD, Georges; NERY JR, Nelson Nery; CAMPOS, Ricardo. 2 ed. rev. e amp. São Paulo: Thompson Reuters, 2019. E-book Kindle (loc. 3894).

ARENDT, Hannah. A Condição Humana. 13 ed. rev. Rio de Janeiro: Forense Universitária, 2020.

ARENDT, Hannah. Origens do totalitarismo: antissemitismo, imperialismo, totalitarismo. São Paulo: Companhia de Bolso, 2013.

BARRETO JUNIOR, Irineu Francisco; NASPOLINI, Samyra Haydêe Dall Farra. Proteção de informações no mundo virtual: a LGPD e a determinação de consentimento do titular para tratamento de dados pessoais. Cadernos Adenauer: Proteção de dados pessoais: privacidade versus avanço tecnológico, n. 3. Rio de Janeiro: Fundação Konrad Adenauer, out. 2019, pg. $137-155$.

BARRETO JUNIOR, Irineu Barreto; SPAREMBERGER, Raquel Fabiana Lopes. Ética e democracia na sociedade da informação. In: Direitos Humanos e Fundamentais na era da informação. SARLET, Ingo Wolfgang; WALDMAN, Ricardo Libel. (Orgs). Porto Alegre, RS: Editora Fundação Fênix, 2020,pg. 175-190.

BBC News. 'Fake news' é eleita palavra do ano e ganhará menção em dicionário britânico. Disponível em: https://www.bbc.com/portuguese/internacional-41843695. Acesso em 10 dez. 2020.

BUCCI, Eugênio. Pós-política e corrosão da verdade. Revista USP. n. 116, p. 19-30, jan/fev/mar 2018.

CASTELLS, Manuel. A sociedade em rede: a era da informação: economia, sociedade e cultura. v.1. São Paulo: Paz e Terra, 2019.

DUARTE, André. Hannah Arendt e a modernidade: esquecimento e redescoberta da política. Trans/Form/Ação, v. 24, p. 249-272, 2001. 
DUNKER, Christian. Subjetividade em tempos de pós-verdade. In: Ética e pós verdade. Porto Alegre: Dublinense, 2017. E-book Kindle (loc. 03-26).

FAUSTINO, André. Fake News. São Paulo: Lura Editorial, 2019.

FIGUEIRA, João. As fake news e a nova ordem (des)informativa na era da pós-verdade. Imprensa da Universidade de Coimbra, 2019. Disponível: https://doi.org/10.14195/978-98926-1778-7. Depósito legal 460408/19.

FOGAROLLI FILHO, Paulo Roberto; WALDMAN, Ricardo Libel. O poder e visibilidade na era da sociedade midiatizada e os riscos para os direitos humanos. In: Os desafios dos direitos humanos na sociedade da informação: volume 2 - Org. DE MARTINI; Sandra Regina; CAVALCANTI; Ana Elizabeth Lapa Wanderley; GALVÃO, Flávio Alberto Gonçalves. Rio Grande do Sul: Editora Fi, 2020. Disponível em: www.editorafi.org. Acesso em 10 dez. 2020, pg. 119-138.

FONSECA, Francisco. Mídia, poder e democracia: teoria e práxis dos meios de comunicação.

Revista Brasileira de Ciência Política. n. 6, p. 41-69, jul-dez, 2011.

G1. Instagram faz dez anos como uma das maiores redes sociais do mundo e de olho no TikTok para não envelhecer. Disponível em: https://g1.globo.com/economia/tecnologia/noticia/2020/10/06/instagram-faz-10-anos-comouma-das-maiores-redes-sociais-do-mundo-e-de-olho-no-tiktok-para-nao-envelhecer.ghtml. Acesso em 10 dez. 2020.

LAFER, Celso. A reconstrução dos direitos humanos: a contribuição de Hannah Arendt. Estudos Avançados, n. 11, p. 55-65, 1997.

LATTMAN-WELTMAN, Fernando. Mídia e democracia: indeterminação e representatividade da representação. Revista Compolítica. n. 4, v. 2, p. 27-57, ago-dez, 2014. LÉVY, Pierre. Cibercultura. Trad. Carlos Irineu da Costa. São Paulo: Ed. 34, 1999.

MACEDO JÚNIOR, Ronaldo Porto. Fake News e as novas ameaças à liberdade de expressão. In: Fake News e Regulação. Org. ABBOUD, Georges; NERY JR, Nelson Nery; CAMPOS, Ricardo. 2 ed. rev. e amp. São Paulo: Thompson Reuters, 2019. E-book Kindle (loc. 7467).

MELlo, Patricia Campos. A máquina do ódio: notas de uma repórter sobre fake News e violência digital. São Paulo: Companhia das Letras, 2020. 
ONU News. Uso de Internet no Mundo. Disponível em: https://news.un.org/pt/tags/uso-deinternet-no-mundo. Acesso em 10 dez. 2020.

PELLIZZARI, Bruno Henrique Miniuchi; BARRETO JUNIOR, Irineu Francisco. Bolhas sociais e seus efeitos na sociedade da informação: ditadura do algoritmo e a entropia na internet. Revista de Direito, Governança e Novas Tecnologias. v. 5, n. 2, p. 57-73, jul-dez 2019. Disponível em: https://www.indexlaw.org/index.php/revistadgnt/article/view/5856. Acesso em 16 dez. 2020.

RAIS, Diogo. Desinformação no contexto democrático. In: Fake News e Regulação. Org. ABBOUD, Georges; NERY JR, Nelson Nery; CAMPOS, Ricardo 2 ed. rev. e amp. São Paulo: Thompson Reuters, 2019. E-book Kindle (loc. 8000).

RECUERO, Raquel. Redes sociais na internet. Porto Alegre: Sulina, 2009.

SERRANO, Estrela. O espaço público e o papel do Estado na sociedade global da informação. Disponível em: http://bocc.ufp.pt/_esp/autor.php?codautor=608. Acesso em 02 set. 2020.

SODRÉ, M. Antropológica do espelho. Petrópolis: Vozes, 2002.

TELLES, Vera da Silva. Espaço Público e Espaço Privado na Constituição do Social: notas sobre o pensamento de Hannah Arendt. Tempo Social. Rev. Soc. USP. v. 2, n. 1, p. 23-48. 1 sem., 1990.

THOMPSON, John B. A nova visibilidade. Revista MATRIZes n. 2, abr. 2008.

TOFOLLI, José Antonio Dias Toffoli. Fake News, desinformação e liberdade de expressão. In: Fake News e Regulação. Org. ABBOUD, Georges; NERY JR, Nelson Nery; CAMPOS, Ricardo. 2 ed. rev. e amp. São Paulo: Thompson Reuters, 2019. E-book Kindle (loc. 370).

TRIVINHO, Eugênio. Glocal: visibilidade mediática, imaginário bunker e existência em tempo real. São Paulo: Annablume, 2012.

VIRILIO, Paul. Velocidade e política. São Paulo: Estação Liberdade. 1996.

WAACK, William. Fake News: uma visão político-jornalística. In: Fake News e Regulação. Org. ABBOUD, Georges; NERY JR, Nelson Nery; CAMPOS, Ricardo. 2 ed. rev. e amp. São Paulo: Thompson Reuters, 2019. E-book Kindle (loc. 7319). 